\title{
EL MUNDO EN MOVIMIENTO: EL CONCEPTO DE REVOLUCIÓN EN IBEROAMÉRICA Y EL ATLÁNTICO NORTE (SIGLOS XVII-XX)
}

Fabio Wasserman (comp.), Buenos Aires, Miño y Dávila, 2019, 295 pp.

La obra que aquí se reseña puede vincularse con dos situaciones historiográficas que resultan clave tanto para comprender el contexto desde el que escriben sus autores, como para valorar su relevancia dentro de la amplísima y diversificada producción sobre los procesos que, grosso modo, podemos incluir dentro de la «era de las revoluciones». Por una parte, los bicentenarios de varias de estas últimas vienen nutriendo desde hace ya tres décadas el debate en torno de las causas, posibilidades, limitaciones y alcances de sus trayectos históricos, reformulando preguntas, construyendo nuevos interrogantes, considerando otros actores, prestando atención a prácticas antes no tenidas en cuenta y estimulando relecturas de fuentes ya visitadas pero que han sido abordadas con intereses inéditos. Por otra parte, aunque sin dejar de estar vinculado a esa reflexión particular que la serie de aniversarios ha generado y sigue haciéndolo, conviene destacar el espacio específico de discusión y producción creado por Iberconceptos (Proyecto y Red de Investigación en Historia Conceptual Comparada del Mundo Iberoamericano) para pensar los lenguajes políticos en su capacidad expresiva de ciertas situaciones sociales, pero también performativa de ellas. En tal sentido, no es casual que un grupo considerable de autores de los capítulos reunidos por Wasserman hayan participado de un modo activo en los eventos y publicaciones de ese rico ámbito de trabajo.

El objetivo central de esta obra colectiva, tal como lo adelanta su compilador, consiste en seguir la configuración de la palabra «revolución» como concepto político fundamental, esto es, como una noción que logra integrar y remitir a distintos significados, incorporando en ellos la realidad social que quiere nombrar y de la que quiere dar cuenta, por lo cual, además, resulta disputada por diversos actores y grupos en diferentes momentos. Así, lejos de partir de una definición a priori busca contribuir a su reconstrucción histórica a partir de las experiencias, las representaciones y los usos lingüísticos de los propios contemporáneos de los sucesos vinculados a su conformación conceptual. Y si bien cada capítulo se ocupa de singulares contextos territoriales, abordados en periodizaciones internas específicas, la compilación logra una unicidad que el lector puede apreciar al terminar de recorrerla. 
En este sentido, resulta claro que la intensidad de las relaciones entre los procesos político-institucionales e ideológicos del mundo atlántico-iberoamericano permite evidenciar, desde el vamos, una integración histórica que resulta no solo evidente para nosotros, que sabemos el final del cuento, sino también para los mismos actores que lo protagonizaron, quienes nunca perdieron de vista la potencialidad del contagio revolucionario. El libro restituye muy bien esa interacción continua en el devenir de los distintos territorios, ello expresado en los préstamos y apropiación de palabras, el enriquecimiento de sus significados, la circulación de modelos gubernamentales conectados con ellos y la difusión de noticias y relatos sobre experiencias que generaban, en el amplio espacio occidental, un capital revolucionario disponible en materia de términos políticos, estrategias exitosas y ejemplos no deseables. En definitiva, si los capítulos adoptan, en general, los marcos geográficos de lo que luego constituirían comunidades estatales nacionales, nunca dejan de tener en cuenta la densidad de los lazos extraterritoriales, la multilinealidad de esos mismos trayectos hasta llegar a conformar efectivamente Estados, y la relevancia de atender a la perspectiva de los actores que no sabían, en definitiva, cuáles serían los límites y fronteras finales de estos.

No obstante, ciertos consensos teórico-metodológicos son también aspectos que contribuyen a la coherencia y cohesión de la obra. Las precisiones de Koselleck respecto de la distinción entre palabra y concepto como criterio básico para seguir la trayectoria de «revolución» desde la primera al segundo, conforma un primer acuerdo que fortalece el lenguaje común de los autores, más allá de los objetos de estudio particulares sobre los cuales lo aplican. Del mismo modo, la noción de modernidad como nueva concepción de la temporalidad atraviesa los textos, en tanto la irrupción de la novedad, la noción de ruptura con el pasado y el enfoque hacia el futuro, aparecen como motor impulsor de la fuerza que va adquiriendo el concepto de «revolución» al ser formulado como horizonte de expectativas y expresivo de una inédita articulación entre el tiempo pretérito, el presente y el porvenir. De allí que no resulta casual que los trabajos asuman una opción metodológica diacrónica, pues, aunque parezca una redundancia, conforma la mejor vía analítica para dar efectivamente cuenta de la historicidad de la palabra y el concepto en cuestión. Un elemento adicional que contribuye a la articulación interna de la obra en su conjunto está conformado por la diversidad de fuentes analizadas y la relevancia otorgada especialmente a aquellas que reflejan el uso social de «revolución», los términos vinculados a su campo semántico y aquellos que se posicionaron en el opuesto. En este registro, si los diccionarios conforman para casi todos los autores una referencia ineludible, del mismo modo que ciertos textos teórico-doctrinarios de época, también apelan a panfletos, anónimos, correspondencia, prensa e, incluso, iconografía, que reflejan modos de utilización que no siempre acuerdan con la intención normativa de ese primer grupo de fuentes que busca, más explícitamente, imponer sentidos al habla. Asimismo, los capítulos atienden a un hecho fundamental no siempre tenido en cuenta a la hora de explicar los procesos de difusión y apropiación de las ideas: circulan los libros, eso es claro, pero también y, sobre todo, circulan las personas, las cuales relatan noticias y rumores, expresan pareceres, convirtiéndose ellas mismas en soporte de la importación y exportación de 
palabras y en vehículos para el enriquecimiento semántico de las ya disponibles. Esta perspectiva subjetiva resulta central a lo largo de la compilación, pues de lo que se trata en ella es de recuperar a los sujetos como actores efectivos, como protagonistas de los hechos que intentan nombrar, recuperando su potencial creador de términos que les permiten dar cuenta de su propia experiencia ante la ineficacia de los existentes. En tal sentido, la noción de que la reformulación de los lenguajes políticos es simultánea (nunca previa) a la experiencia histórica, atraviesa transversalmente la obra, incluso cuando los autores muestran cómo los actores reinterpretan los hechos pasados, y ello porque logran evidenciar cómo lo hacen desde una coyuntura presente que informa sus modos de verlos y nombrarlos.

Fabio Wasserman ha reunido diez trabajos que se corresponden con sendos capítulos, en los cuales, como se dijo, se despliega ese haz de consideraciones comunes en el estudio de casos particulares que cubren un muy amplio espectro temporal y espacial, y lo hacen con estrategias propias más allá del acuerdo teórico-metodológico mencionado. Así, Nicolás Kwiatkowski se ocupa del concepto de «revolución», en el ámbito inglés durante el siglo XVII, retomando un conjunto de argumentaciones historiográficas que aborda críticamente desde su personal indagación empírica. Marcos Reguera, a su vez, propone explorar las relaciones semánticas y los solapamientos entre los conceptos de «revolución» y «experimento», en el marco del proceso emancipador estadounidense en un sentido lato, es decir, incluyendo las coyunturas y los contextos de un amplio periodo que va desde los momentos previos a la crisis colonial hasta la consolidación de la república americana. La centralidad del caso francés como clivaje fundamental en la politización y modernización del concepto de «revolución» es asumida por Jacques Guilhaumou, quien remarca con insistencia la necesidad de atender el anclaje social de la conceptualización política, como espacio de experiencia que permite dar cuenta de las necesidades comunicacionales de las vivencias individuales y colectivas. Por su parte, la simultaneidad de los acontecimientos metropolitanos en Francia con los de sus colonias antillanas es analizada por Alejandro Gómez, quien se enfoca en la polisemia desarrollada por el concepto en estudio a lo largo de las revueltas que culminaron con la independencia de Haití en 1804, marcadas por la complejidad que el componente étnico-racial introducía en las relaciones sociopolíticas locales. Javier Fernández Sebastián y Gonzalo Capellán de Miguel ofrecen un panorama secular de las trayectorias conceptuales de «revolución», en los diversos contextos político-institucionales de la España decimonónica, en los cuales fue apropiado, reemplazado, rechazado o resignificado para servir diversos proyectos ideológicos y gubernamentales. El cercano caso portugués es tomado por Fátima Sá e Melo Ferreira, quien reconstruye para los cien años transcurridos entre 1770 y 1870 los sentidos positivos y negativos que nutrieron el uso de la palabra, las tramas semánticas en las que esta se insertó y los actores políticos que articularon esos significados según su intencionalidad dentro de la deriva institucional. El propio compilador, de hecho, es autor del capítulo dedicado al Río de la Plata durante el periodo extendido entre las reformas borbónicas y los inicios del proceso constituyente nacional; su opción consiste en centrarse en la configuración del sintagma «Revolución de Mayo» como mito de 
los orígenes de la nación argentina, acumulando diversos sustratos semánticos que contribuyeron también a la densificación misma del concepto «revolución». Los territorios de Tierra Firme, esto es, aquellos sobre los que se configurarían Colombia y Venezuela como estados independientes, son abordados por Alexander Chaparro Silva, que analiza cómo la dinámica de esa espacialidad influyó en la circulación de palabras y personas, atravesando con ello los usos de «revolución», una palabra que terminó constituyéndose en un concepto con sentidos antagónicos. Finalmente, los dos últimos trabajos asumen una mirada de larga duración: tanto Guillermo Zermeño para México, como Joõo Paulo Pimenta y Rafael Fanni para Brasil, ofrecen una perspectiva plurisecular que les permite explicar cómo el concepto se convirtió en referente clave para la construcción de la nación como proyecto común, esto es, como una noción guía de referencia colectiva en materia de interpretaciones de distintos pasados, articulador de posibles presentes y promesa de futuros alternativos.

Ahora, ¿Qué dice efectivamente este conjunto de estudios sobre la configuración de «revolución» como concepto político fundamental, esto es, disputado en sus sentidos y usos dada la riqueza semántica que logra contener? Lo primero que resulta claro después de haber concluido la lectura (sea que ésta haya seguido el orden propuesto en la organización de la obra o se haya realizado en forma salteada), es que desde fines del siglo XVIII, e incluso antes, tal como lo muestra el ejemplo inglés, han convivido diversas significaciones, tanto positivas como negativas, dependiendo del gusto e intención del hablante, aunque sí es claro el abandono progresivo dentro del lenguaje político de la noción de retorno o repetición para consolidarse, en cambio, la de cambio súbito o novedad. En este registro, en el marco de una contienda semántica, la articulación coyuntural con «regeneración» y «reforma», ha expresado los momentos en los que el desprestigio y/o banalización del concepto tanto como su incapacidad para proyectar un horizonte de expectativas, habilitó el espacio para otros términos con un capital político nominativo que generó mayores márgenes de movimiento a los actores implicados. En segundo lugar, también resulta evidente que la Revolución Francesa impuso un clivaje indiscutible dentro de los usos vigentes en su momento, ofreciendo una experiencia histórica de referencia, buena o mala según quién la mirara, pero que resultó ineludible en el amplio espacio iberoamericano decimonónico. En tercera instancia, los análisis dan cuenta de la fuerza conceptual de «revolución» a los fines de construcción de un proyecto nacional, permitiendo la apropiación de ciertos pasados y la invisibilización de otros en función de la delineación de un relato histórico determinado como sustento del Estado en su etapa formativa, e incluso después, para afrontar problemas relacionados con la inclusión y exclusión implicada en la implementación efectiva de la ciudanía. Finalmente, si hay algo que se impone como conclusión final al terminar la lectura de la obra, es la historicidad del concepto político de «revolución», y con ello su carácter abierto y proteico en tanto continúa reformulándose, cargándose de nuevas significaciones, y sigue siendo disputado por los más diversos actores para legitimar muy distintos órdenes políticos y, por ende, sociales. De tal forma, ya instituido como horizonte de expectativas, sigue densificándose según las intencionalidades del hablante, y es claro que estas tienen que ver con lo que se espere de las rela- 
ciones entre el Estado y la sociedad, las responsabilidades del primero respecto de la segunda, sus proyecciones y sus limitaciones, lo cual conforma un debate inacabado y siempre recurrente.

Eugenia Molina

IDEHESI-CONICET - UNCuyo

(Mendoza, Argentina) 